\title{
Disconfirmation of confirmation bias: the influence of counter-attitudinal information
}

\author{
Pauline Dibbets $^{1} \cdot$ Cor Meesters $^{2}$ \\ Published online: 25 April 2020 \\ (C) The Author(s) 2020
}

\begin{abstract}
The current experiment investigated whether counter-attitudinal information can alter a pre-existing attitude and the accompanying confirmation bias. Sixty-three non-clinical children (9-12 years) were shown pictures of a positive animal (quokka) or a dangerouslooking animal (aye aye). For both animals attitudes and information seeking patterns were obtained. Next, they received counterattitudinal information of each animal; attitudes and seeking patterns were reassessed. We found that the aye aye was perceived as more dangerous and less kind compared to the quokka. A negative confirmation bias was observed for the aye aye, more negative than positive or neutral information was requested. For the quokka this pattern was absent, more positive and negative than neutral information was selected. The counter-attitudinal information decreased the scariness of the aye aye, but did marginally alter that of the quokka. Additionally, for the aye aye counter-attitudinal information increased search for positive and neutral information and decreased search for negative information. For the quokka the counter-attitudinal information only increased search for neutral information. The animals no longer differed from each other and no clear confirmation bias patterns were present. These results indicate that it is possible to change pre-existing values and their accompanying information search patterns.
\end{abstract}

Keywords Confirmation bias $\cdot$ Anxiety $\cdot$ Children $\cdot$ Counter-attitudinal information $\cdot$ Information seeking

\section{Introduction}

Anxiety disorders are among the most prevalent mental disorders in childhood (Merikangas et al. 2009), hamper daily functioning and tend to persist into adulthood (Bandelow and Michaelis 2015). It is, therefore, necessary to examine processes linked to the onset and maintenance of anxiety disorders in order to improve or develop effective interventions.

Current theoretical frameworks state that information processing deficits are at the base of anxiety disorders (Beck and Clark 1997; Eysenck et al. 2007; Ouimet et al. 2009). Anxious people display several information processing biases that are not, or to a lesser extent, observed in non-anxious persons

Pauline Dibbets

Pauline.Dibbets@maastrichtuniversity.nl

Cor Meesters

C.Meesters@maastrichtuniversity.nl

1 Clinical Psychological Science, Maastricht University, P.O. Box 616, 6200, MD Maastricht, The Netherlands

2 Faculty of Psychology and Neuroscience, Maastricht University, Maastricht, The Netherlands
(Ouimet et al. 2009). A bias that has lately gained attention is confirmation bias. This bias is expressed in the tendency to search for information that confirms the (negative) view a person holds, while ignoring alternative information that challenges the current view. Such preference for verification over falsification strategy then automatically results in the reinforcement and maintenance of the fear (De Jong et al. 1997; Mathews and MacLeod 2005).

Several studies have indicated that (indirectly) establishing a negative view in children results in inclined search for information that confirms this view (Muris et al. 2011; Muris et al. 2009; Remmerswaal et al. 2010). Even the mere perception of threat, without explicit establishment, is sufficient to encourage such strategy (Dibbets et al. 2014; Dibbets and Meesters 2017). The search for negative information can in turn enhance fear levels, indicating a reciprocal relationship between fear and confirmation bias (Dibbets and Meesters 2017; Remmerswaal et al. 2014).

In the studies by Muris and colleagues, children received negative, positive or ambiguous information about an unknown animal. The attitudes towards the animal changed in line with the (indirectly) provided information. However, this change was not equally strong. Providing negative information resulted in a stronger change in attitude than providing 
positive information (Muris et al. 2009; Remmerswaal et al. 2014). This imbalance in change in attitudes is not limited to fear attitudes (Dibbets et al. 2012). In general, bad impressions and stereotypes are faster to form and more resilient to disconfirmation than good ones (Baumeister et al. 2001).

As information can affect attitudes and attitudes are reflected in search for information, a logical deduction would be that changes in attitudes should also be reflected in changes in search for information. Though the objective of previous studies was not to link changes in attitudes to confirmation bias, the results seem indicative of such relationship. Providing negative information resulted in a strong change in attitude. This negative attitude was subsequently reflected in a negative confirmation bias pattern with an increased search for negative information. However, providing positive information did not yield equal decreases in attitude; the decrease was not - or only weakly - reflected in increased search for positive information (Muris et al. 2009; Remmerswaal et al. 2014). Though this seems to imply that a change in attitude results in an accompanying change in confirmation bias, this cannot directly be deduced from these data. Confirmation bias was only measured once, so no change in bias could be observed.

The current study is set up to fill this gap and seeks to link alterations in attitude to changes in confirmation bias in children. To this end, emotionally valued stimulus material will be used: a positively valued unfamiliar animal, the quokka, and a negatively valued unknown animal, the aye aye (cf. Dibbets et al. 2014; Dibbets and Meesters 2017). Baseline attitudes and search for information about these animals will be assessed. Subsequently, counter-attitudinal information will be provided and the attitude towards the animals and confirmation bias will be reassessed. Based on previous studies, it is hypothesized that it is easier to increase the negative value of the quokka than to decrease the aversiveness of the aye aye. Secondly, we expect that a putative change in attitude will result in a change in confirmation bias patterns. This change will, probably, be mostly pronounced after providing negative counter-attitudinal information (quokka) and not, or to a lesser extent, after positive information (aye aye).

The results of this study are important, because if providing alternative information affects attitudes and, subsequently, accompanying confirmation bias patterns, this may provide a starting point for further development of anxiety treatments and preventions.

\section{Methods}

\section{Participants}

The sample consisted of sixty-three Dutch children (27 boys, 36 girls), aged $9-12$ years $(M=10.44, S D=10$ months $)$ recruited via a regular primary school. Parents received an information letter and an informed consent. Of the parents, the majority was Dutch $(87.1 \%), 4.7 \%$ had the German nationality, $4.7 \%$ had the Indonesian nationality and the parents of the remaining children had different nationalities (e.g., Moroccan, Turkish and Italian). Children with a history of anxiety problems were excluded from participation. The study was carried out in line with the declaration of Helsinki (Williams 2008) and approved by the local ethical committee (approval code: 178_11_04_2017).

\section{Animals}

Two animals were used for the current study, the quokka and the aye aye (cf. Dibbets et al. 2014; Dibbets and Meesters 2017). In a previous study the aye aye was rated as threatening and negative, whereas the quokka received positive ratings. The pictures were printed on a separate paper $\left(163 \mathrm{~cm}^{2}\right)$ or presented via a computer screen and labelled with the species name (see Fig. 1).

\section{Fear Beliefs Questionnaire}

Two distinct Fear Beliefs Questionnaires, FBQs, were filled out; one for the quokka and one for the aye aye (cf. Dibbets et al. 2014; Dibbets and Meesters 2017; Muris et al. 2009). A picture of the animal questioned accompanied the questionnaire. The questionnaire was adjusted, that is, next to the 10 statements that measured the amount of fear, 10 statements about how much the child liked the animal were included. An example of a fear-related item is as follows: "Would you find it scary to touch a quokka?" and of a likeability item "Would you like to play with the quokka?" Children could rate these items on a 5-point Likert scale ranging from "No, not at all" to "Yes, definitely". Per animal a total fear score and likeability score can be calculated by summing the ratings on all related items (range 10-50). Cronbach's alpha for the subscales ranged from .77 (quokka fear-related) to .95 (aye aye likeability).

\section{Attitudes towards the Animals}

Attitudes towards the animals were assessed by printed and computerized Visual Analogue Scales, VASprint and VASpc, respectively. The printed version consisted of two negative (e.g.,"Do you think that the quokka is a dangerous animal?") and two positive items (e.g., "Do you think that the aye aye is a kind animal?"). The scores of the two negative and of the two positive items were averaged to a respectively, negative and positive valence score. In the computerized version, the child was asked for the scariness of the animal. All scores ranged between 0 (not at all) to 100 (extremely). The computerized version was added as it allowed a fast, immediate 
Fig. 1 Picture of the quokka (left) and aye aye (right)
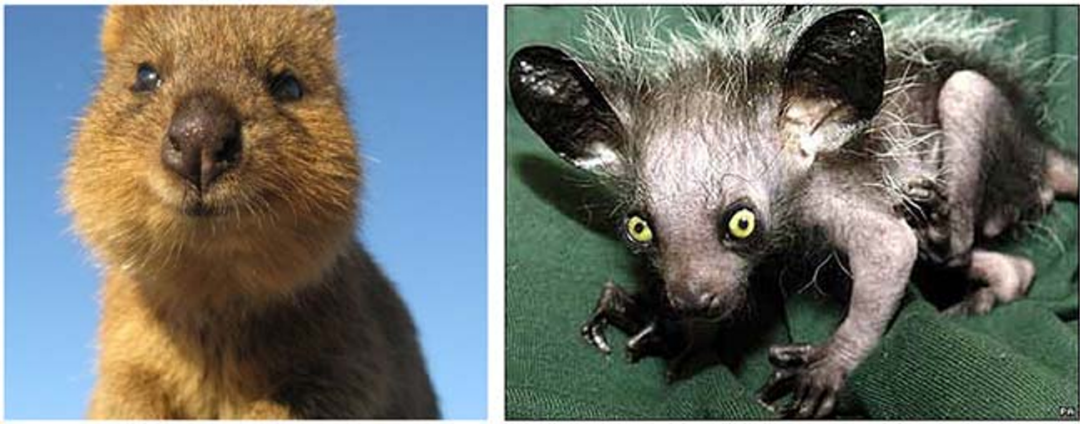

valence rating of the animals before, in between and after the confirmation bias tasks. In total, the VASpc was offered four times for each animal (VASpc\#1, VASpc\#2, VASpc\#3 and VASpc\#4).

\section{Confirmation Bias}

The confirmation bias task strongly resembled that of previous research (Dibbets et al. 2014; Dibbets and Meesters 2017; Remmerswaal et al. 2015). The task was programmed using e-prime 2.0 (Psychology Software Tools, Pittsburgh, PA; Schneider et al. 2012) and ran on a laptop connected to a 24 in. monitor. In this task, the tendency to search for positive, neutral and negative information was measured. For each animal 12 trials were administered; the VASpc was presented before and after these trials (VASpc\#1 and VASpc\#2, respectively). A trial started with the presentation of the following question on the screen: "What do you further want to know about the quokka/aye aye?". The child could select one of three information options at the bottom of the screen: a negative option (e.g., "I want to know if the aye aye eats other animals"), a neutral option (e.g., "I want to know if the aye aye eats green leafs") and a positive option ("I want to know if the aye aye eats delicious fruits"). The order of the information options systematically varied across trials. The picture of the particular animal was presented at the middle of the computer screen, between the question and information options. After selection, a confirmative answer was displayed. For example, selection of the neutral option "I want to know if the aye aye eats green leafs" would result in the answer "Yes, the aye aye eats green leaves". For each animal two sets of information options were available so that the task could be presented twice. The number of positive, neutral or negative selection choices were summed up per animal. Both the set of information options and the order in which the animals were presented were counterbalanced across participants.

\section{Selection of Information Task}

The selection of information task (SIT) consists of 9 statements about each animal. Of these statements 3 are positive, 3 negative and 3 neutral; the order of the items is random. The child is requested to select three statements per animal.

\section{Counter-Attitudinal Information}

For both the aye aye and the quokka an imaginary Wikipedia page was made, containing counter-attitudinal information. Each page contained information about the animal's habitat, eating pattern, family life and response to humans. The text was accompanied by a (novel) picture of the animal. For the aye aye positive statements were presented; for the quokka negative information was provided.

\section{Procedure}

Children were tested in their classroom under supervision of two research assistants. The assistants guided the children through the session by providing instructions, exemplifying several questionnaires and they ensured that children did not consult each other during testing. Children filled out the FBQs and VASprint for each animal. Children seated next to each other were provided with different versions of the questionnaires (e.g., some children started with the FBQ concerning the quokka, others with the FBQ regarding the aye aye). Subsequently, the confirmation task was individually conducted in a separate room. The order of animals during the confirmation bias task was similar to that of the questionnaires (confirmation bias I). Before and after the confirmation bias task of each animal, the children rated that particular animal with the VASpc (VASpc\#1 and VASpc\#2, respectively). After completion of the confirmation bias task for both animals, children received counter-attitudinal information about the first animal. Next, the second confirmation bias task (confirmation bias II) and VASpc (VASpc\#3 and VASpc\#4, respectively) of this particular animal were presented. This procedure was repeated for the remaining animal. Finally, they completed the SIT. Debriefing took place after the last participant was tested. 


\section{Statistical Analyses}

A total of 7 out of 3024 items of the confirmation bias answers were missing. These incomplete sumscores (frequency of positive, negative and neutral answers) were proportionally corrected. The questionnaire and VAS data were analyzed parametrically (General Linear Model with repeated measures, GLM); the SIT selection (number of selected negative, neutral or positive statements) was analyzed by means of nonparametric tests (Wilcoxon Signed Ranks test). Main effects are not reported in case of an interaction. Bonferroni Holm corrections were made in case of multiple comparisons. In case of violation of sphericity Greenhouse-Geisser corrections were made. The rejection criterion was set at $p<.05$.

\section{Results}

\section{Attitudes towards Animals}

Table 1 summarizes the questionnaire data. A GLM with animal (quokka and aye aye) and valence (likeability and fearrelated) was run on the FBQ data. This analysis revealed an interaction between animal and valence, $F(1,62)=105.40$, $p<.001, \eta \rho^{2}=.63$. Separate GLMs for the likeability and fear-related data indicated that the quokka received higher likeability ratings, $F(1,62)=108.17, p<.001, \eta \rho^{2}=.64$, and lower fear-related ratings, $F(1,62)=78.69, p<.001$,

Table 1 Mean scores (SDs) on the questionnaires and tests concerning the animals

\begin{tabular}{llr}
\hline & Quokka & Aye aye \\
\hline FBQ & & \\
$\quad$ Likeability & $36.54(9.16)$ & $25.89(10.29)$ \\
Fear & $21.46(5.59)$ & $30.02(8.93)$ \\
VASprint & & \\
Positive & $60.75(21.53)$ & $33.19(24.20)$ \\
Negative & $46.21(13.09)$ & $59.94(21.47)$ \\
VASpc & & \\
VASpc\#1 & $22.98(22.84)$ & $58.22(26.95)$ \\
VASpc\#2 & $23.65(23.72)$ & $56.84(28.68)$ \\
VASpc\#3 & $24.29(22.91)$ & $40.35(27.18)$ \\
VASpc\#4 & $30.60(26.70)$ & $39.32(28.25)$ \\
SIT & & $1.14(.79)$ \\
Positive & $1.16(.84)$ & $.78(.72)$ \\
Neutral & $.78(.75)$ & $1.08(.90)$ \\
Negative & $1.06(.89)$ & \\
\hline
\end{tabular}

Note. $\mathrm{FBQ}=$ Fear Beliefs Questionnaire; VASprint = printed Visual Analogue Scales; VASpc = computerized Visual Analogue Scales; SIT $=$ Selection of Information Task $\eta \rho^{2}=.56$, than did the aye aye. A similar GLM was run on the VASprint data. In this analysis valence (positive and negative) and animal (quokka and aye aye) served as within subjects factors. This analysis yielded an animal $\mathrm{x}$ valence interaction, $F(1,62)=59.69, p<.001, \eta \rho^{2}=.49$. Separate GLMs for the negative and positive scores indicated that the quokka was perceived as more positive, $F(1,62)=68.90, p<.001$, $\eta \rho^{2}=.53$, and less negative, $F(1,62)=19.09, p<.001$, $\eta \rho^{2}=.24$, than the aye aye. The first VASpc also indicated that the aye aye was rated scarier than the quokka, $F(1$, $62)=62.30, p<.001, \eta \rho^{2}=.50$. In sum, these results indicate that the aye aye was perceived as more negative and threatening than the quokka.

\section{Confirmation Bias I}

The confirmation bias data (I and II) are represented in Fig. 2. A GLM was run with animal (quokka and aye aye) and information type (frequency of positive, neutral and negative choices) as within-subjects factors. This analysis yielded an animal $\mathrm{x}$ information type interaction, $F(2,124)=19.40$, $p<.001, \eta \rho^{2}=.24$. Separate GLMs were run per animal to assess the search for information patterns. Both analyses revealed main effects for type of information, $F \mathrm{~s}(2,124)>6.81$, $p \mathrm{~s}<.003, \eta \rho^{2}>.098$. Pairwise comparisons indicated that for the quokka no specific confirmation bias pattern was observed, the children requested more negative and positive than neutral information, $p s<.003$. No difference between negative and positive information was observed, $p=.85$. For the aye aye more negative than neutral and positive information was requested, $p \mathrm{~s}<.001$, and more positive than neutral information was asked for, $p=.007$. Direct comparisons between the animals indicated that, compared to the aye aye, for the quokka more positive, $F(1,62)=16.64, p<.001$, $\eta \rho^{2}=.21$, more neutral, $F(1,62)=6.95, p=.011, \eta \rho^{2}=.10$, and less negative information, $F(1,62)=26.43, p<.001$, $\eta \rho^{2}=.30$, was requested.

\section{Change in Attitude I}

The scariness of both animals before (VASpc\#1) and after the confirmation bias task (VASpc\#2) was assessed. A GLM repeated measures with time (VASpc\#1 and VASpc\#2) and animal (quokka and aye aye) as within-subject factors was run. The GLM indicated that, overall, the aye aye received higher scariness ratings than did the quokka, $F(1,62)=77.67$, $p<.001, \eta \rho^{2}=.56$, no effect of time of interaction were observed, $F_{\mathrm{S}}<1$. Providing the counter-attitudinal information did change the VASpc scariness ratings, as the GLM did revealed an interaction between time (VASpc\#2 before counterattitudinal information and VASpc\#3 after information) and animal (quokka and aye aye), $F(1,620=13.11, p=.001$, $\eta \rho^{2}=.17$. Separate GLMs per animal indicated that the 
Fig. 2 Mean response patterns and SEMs for confirmation bias task I (left side) and task II (right side)

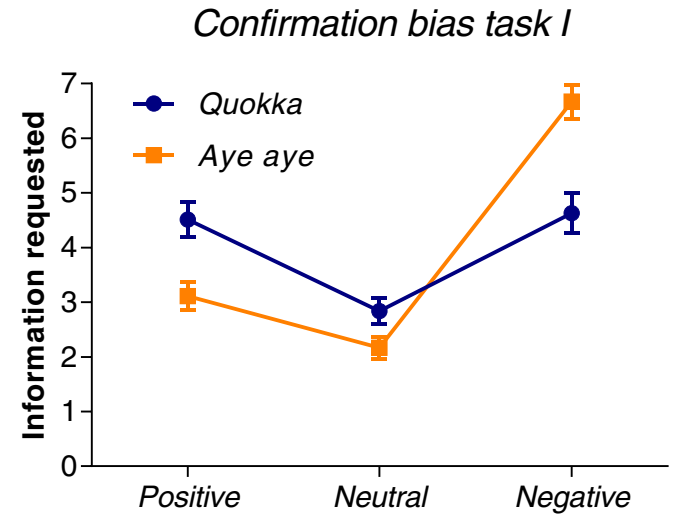

Confirmation bias task I

Confirmation bias task II

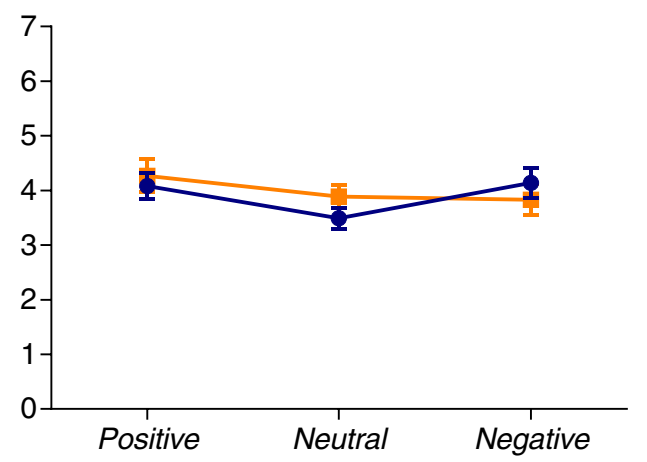

scariness ratings of the aye aye decreased, $F(1,62)=20.91$, $p<.001, \eta \rho^{2}=.25$, no change in ratings for the quokka was observed, $F<1$. Note that after the information the aye aye was still rated as scarier than the quokka, $F(1,62)=13.69$, $p<.001, \eta \rho^{2}=.18$.

\section{Confirmation Bias II}

The GLM with animal (quokka and aye aye) and information type (number of positive, neutral and negative information choices) as within-subjects factors Revealed no (interaction) effects, $F \mathrm{~s}<1$. Separate analyses per animal revealed that for both animals no main effect of information was observed, $F \mathbf{s}$ $<1$. These results indicated that the children did not have a specific preference for one type of information, regardless of the animal.

\section{Change in Attitude II}

The scariness of the animals was assessed before and after the second confirmation bias task, VASpc\#3 and VASpc\#4, respectively. A GLM with time and animal as within-subjects factors revealed a main effect of animal, $F(1,62)=12.42$, $p=.001, \eta \rho^{2}=.17$, and a marginally significant interaction between time and animal, $F(1,62)=3.47, p=.067$, $\eta \rho^{2}=.053$. This nearly-significant interaction was caused by the tendency of an increase in scariness for the quokka, $F(1$, $62)=2.99, p=.089, \eta \rho^{2}=.046$, and the absence of a significant change in the aye aye, $F<1$.

\section{Change in Confirmation Bias}

A GLM with time (before and after counter-attitudinal information), animal (quokka and aye aye) and selected information type (number of positive, neutral and negative choices) as within-subject factors was run. This analysis yielded a time $\mathrm{x}$ animal $\mathrm{x}$ information interaction, $F(2,124)=11.84, p<.001$, $\eta \rho^{2}=.16$. For all types of information an interaction between time and animal was observed, $F \mathrm{~s}(1,62)>4.80, p \mathrm{~s}<.05$, $\eta \rho^{2}>.071$. Separate GLMs per animal and information type indicated that for the quokka only an increase in search for neutral information was observed, $F(1,62)=8.65, p=.005$, $\eta \rho^{2}=.12$, whereas no significant changes in negative or positive information were observed, $F_{\mathrm{s}}(1,62)<1.07, p \mathrm{~s}>.30$, $\eta \rho^{2}<.017$. For the aye aye an increase in search for positive, $F(1,62)=8.01, p=.006, \eta \rho^{2}=.11$, and neutral information, $F(1,62)=40.70, p<.001, \eta \rho^{2}=.40$, was observed, and a decrease in negative information, $F(1,62)=40.95, p<.001$, $\eta \rho^{2}=.40$. These results indicate that presenting counterattitudinal information can change information search patterns.

\section{Selection of Information (SIT)}

Wilcoxon signed ranks tests indicated that for both the aye aye and the quokka more positive than neutral options were selected, $|Z| \mathrm{s}>2.21, p \mathrm{~s}<.044$. No differences were observed between the animals, $|Z| \mathrm{s}<.27, p \mathrm{~s}>.79$.

\section{Discussion}

The present study examined the influence of counterattitudinal information on confirmation bias in children. Sixty-three non-clinical children were invited to search information about the dangerous-looking aye aye and the kindlyperceived quokka (confirmation bias I). Counter-attitudinal information about each animal was provided followed by a repetition of the confirmation bias task (confirmation bias II). Additionally, fear beliefs (FBS) and attitudes (VASprint and VASpc) and selection of information (SIT) were measured.

The aye aye was rated as more negative than the quokka. This negative attitude was reflected in the search pattern during confirmation bias I, more negative information was requested for the aye aye and less positive and neutral information. These results are in line with previous research on confirmation bias in children (Dibbets et al. 2014; Dibbets and Meesters 2017; Muris et al. 2011; Muris et al. 2009; 
Remmerswaal et al. 2010). Presenting counter-attitudinal information resulted in a decreased scariness for the aye aye, this change was also visible in the subsequent confirmation bias task. Compared to the first task, a decrease in negative information and an increase in positive and neutral information were observed. Providing negative information about the quokka tended to increase the scariness of the animal; additionally, an increase in search for neutral information was observed. Furthermore, at the end, when free to select statements, for both animals more positive than neutral items were selected.

The results are not in line with our expectations and previous research. Contrary to our hypotheses, providing positive information about the negatively rated aye aye resulted in an altered search for information. Providing negative information only marginally affected the scariness of the quokka and was not reflected in a subsequent increase in search for negative information. A possible explanation is that the increased likeability functioned as a buffer for the negative information. As the difference in likeability surpassed the difference in fear between the animals, $F(1,62)=9.58, p=.003, \eta \rho^{2}=.13$, it might be more difficult to adjust the former than the latter. An alternative explanation is that the provided information differed in valence. Thought we tried to control for the topics discussed, it might be the case that the negative information was not as strongly valued as the positive information. Unfortunately, we did not rate the value of the fake information provided. For a next study, we would advise to incorporate this measurement or to pilot the Wiki pages used to ensure that the information is equally strongly valued.

The current experiment indicates that it is relatively easy to change the attitudes towards the animals. However, this change is not straightforwardly reflected in subsequent search behaviour. This might be due to a discrepancy between the explicit attitude measurements (VASpc and VASprint) and the more implicit selection tasks. In the attitude measurements, the children are explicitly asked to value the animals; whereas the search for information tasks do not mention the value of the animals, but simply invite the children to gather information. Explicit attitudes more quickly change in response to relatively small amounts of counter-attitudinal information. This is thought to reflect rule-based reasoning, in which children have to solve two competing propositions (e.g., the quok$\mathrm{ka}$ is sweet vs. the quokka is evil), resulting in an attitude change to resolve this inconsistency (Gawronski and Bodenhausen 2006). On the other hand, implicit attitudes are modified by a slow-learning, associative system of evaluation. They are less malleable and need more counter-attitudinal information in order to change (Rydell et al. 2007). Therefore, it is not certain that a change in explicit attitude will be immediately reflected in subsequent (search) behaviour. For future research, it might be interesting to use multiple sessions to promote more thorough establishment of both explicit and implicit attitude changes and test the trajectories of these changes during information bias tasks.

Admittedly, the present study suffers from several limitations. Firstly, we did not observe a positive confirmation bias for the quokka (confirmation bias I). Though the quokka was perceived as more kind, this did not result in increased search for positive information. Even more, the amount of positive and negative information requested did not differ from each other. However, when we take a closer look at the data we do see that increased likeability (FBQ) and a more positive VASprint score, coincide with increased search for positive information, $r \mathrm{~s}>.28, p \mathrm{~s}<.023$, and, if any, with a decreased search for negative information, $r=-.26, p=.040$. These results do suggest the presence of a positive confirmation bias.

A second limitation is that we only included children without anxiety problems. Therefore, we cannot generalize our results to a clinical population. The pre-existing attitudes regarding the novel animals might be rather weak compared to established fears, making these attitudes more susceptible to change than clinical fears. A next logical step for future research would be to replicate current findings with more firmly established attitudes (e.g., spider fear) and, thereafter, to examine the influence of counter-attitudinal information in a clinical sample.

In conclusion, we demonstrated that change in attitude results in a change in confirmation bias patterns. This effect was most obvious after providing positive information. Though unexpected, this is promising as this might indicate that it is possible to adjust negative views and their accompanying information search patterns. This observation can help to explore further techniques to alleviate anxiety problems.

Acknowledgments The authors would like to thank Carmen Poddighe and Liza Fischer for their help during data-acquisition. We would also like to thank the schools, parents and children for their contribution.

Funding This research did not receive any specific grant from funding agencies in the public, commercial, or not-for-profit sectors.

\section{Compliance with Ethical Standards}

\section{Conflict of Interest The authors have no conflict of interest.}

Open Access This article is licensed under a Creative Commons Attribution 4.0 International License, which permits use, sharing, adaptation, distribution and reproduction in any medium or format, as long as you give appropriate credit to the original author(s) and the source, provide a link to the Creative Commons licence, and indicate if changes were made. The images or other third party material in this article are included in the article's Creative Commons licence, unless indicated otherwise in a credit line to the material. If material is not included in the article's Creative Commons licence and your intended use is not permitted by statutory regulation or exceeds the permitted use, you will need to obtain permission directly from the copyright holder. To view a copy of this licence, visit http://creativecommons.org/licenses/by/4.0/. 


\section{References}

Bandelow, B., \& Michaelis, S. (2015). Epidemiology of anxiety disorders in the 21st century. Dialogues in Clinical Neuroscience, 17(3), 327335 .

Baumeister, R. F., Bratslavsky, E., Finkenauer, C., \& Vohs, K. D. (2001). Bad is stronger than good. Review of General Psychology, 5(4), 323-370.

Beck, A. T., \& Clark, D. A. (1997). An information processing model of anxiety: Automatic and strategic processes. Behaviour Research and Therapy, 35(1), 49-58.

De Jong, P. J., Mayer, B., \& Van Den Hout, M. (1997). Conditional reasoning and phobic fear: Evidence for a fear-confirming reasoning pattern. Behaviour Research and Therapy, 35(6), 507-516. https:// doi.org/10.1016/S0005-7967(96)00124-6.

Dibbets, P., \& Meesters, C. (2017). The influence of stimulus valence on confirmation bias in children. Journal of Behavior Therapy and Experimental Psychiatry, 54, 88-92.

Dibbets, P., Adolphs, L., Close, I., Herings, A., Kiggen, M., Kinneging, M., et al. (2012). Reversal of attitude: The influence of counterattitudinal information. Journal of Social Sciences, 8(3), 390-396. https://doi.org/10.3844/jssp.2012.390.396.

Dibbets, P., Fliek, L., \& Meesters, C. (2014). Fear-related confirmation bias in children: A comparison between neutral- and dangerouslooking animals. Child Psychiatry \& Human Development, 1-8. doi:https://doi.org/10.1007/s10578-014-0481-3.

Eysenck, M. W., Derakshan, N., Santos, R., \& Calvo, M. G. (2007). Anxiety and cognitive performance: Attentional control theory. Emotion, 7(2), 336-353.

Gawronski, B., \& Bodenhausen, G. V. (2006). Associative and propositional processes in evaluation: An integrative review of implicit and explicit attitude change. Psychological Bulletin, 132(5), 692.

Mathews, A., \& MacLeod, C. (2005). Cognitive vulnerability to emotional disorders. Annual Review of Clinical Psychology, 1, 167-195. https://doi.org/10.1146/annurev.clinpsy.1.102803.143916.

Merikangas, K. R., Nakamura, E. F., \& Kessler, R. C. (2009). Epidemiology of mental disorders in children and adolescents. Dialogues in Clinical Neuroscience, 11(1), 7-20.
Muris, P., Rassin, E., Mayer, B., Smeets, G., Huijding, J., Remmerswaal, D. 1., \& Field, A. (2009). Effects of verbal information on fearrelated reasoning biases in children. Behaviour Research and Therapy, 47(3), 206-214.

Muris, P., Huijding, J., Mayer, B., van As, W., \& van Alem, S. (2011). Reduction of verbally learned fear in children: A comparison between positive information, imagery, and a control condition. Journal of Behavior Therapy and Experimental Psychiatry, 42(2), $139-144$.

Ouimet, A. J., Gawronski, B., \& Dozois, D. J. A. (2009). Cognitive vulnerability to anxiety: A review and an integrative model. Clinical Psychology Review, 29(6), 459-470.

Remmerswaal, D., Muris, P., Mayer, B., \& Smeets, G. (2010). "Will a cuscus bite you, if he shows his teeth?" inducing a fear-related confirmation bias in children by providing verbal threat information to their mothers. Journal of Anxiety Disorders, 24(5), 540-546. Doi: https://doi.org/10.1016/j.janxdis.2010.03.012.

Remmerswaal, D., Huijding, J., Bouwmeester, S., Brouwer, M., \& Muris, P. (2014). Cognitive bias in action: Evidence for a reciprocal relation between confirmation bias and fear in children. Journal of Behavior Therapy and Experimental Psychiatry, 45(1), 26-32. https://doi.org/ 10.1016/j.jbtep.2013.07.005.

Remmerswaal, D., Muris, P., \& Huijding, J. (2015). Transmission of cognitive bias and fear from parents to children: An experimental study. Journal of Clinical Child \& Adolescent Psychology, 1-13. https://doi.org/10.1080/15374416.2014.987378.

Rydell, R. J., McConnell, A. R., Strain, L. M., Claypool, H. M., \& Hugenberg, K. (2007). Implicit and explicit attitudes respond differently to increasing amounts of counterattitudinal information. European Journal of Social Psychology, 37(5), 867-878.

Schneider, W., Eschman, A., \& Zuccolotto, A. (2012). E-prime reference guide. Pittsburgh: Psychology Software Tools, Inc.

Williams, J. (2008). Revising the declaration of Helsinki. World Medical Journal, 54(4), 120-124.

Publisher's Note Springer Nature remains neutral with regard to jurisdictional claims in published maps and institutional affiliations. 